UDC 519.21

DOI: $10.20535 / 1810-0546.2016 .4 .72344$

\author{
O.I. Klesov ${ }^{1}$, U. Stadtmüller ${ }^{2}$ \\ ${ }^{1}$ National Technical University of Ukraine "KPI", Kyiv, Ukraine \\ ${ }^{2}$ University of Ulm, Ulm, Germany

\section{EXISTENCE OF MOMENTS OF EMPIRICAL VERSIONS OF HSU-ROBBINS-BAUM-KATZ SERIES}

\begin{abstract}
Background. We study the so called empirical versions of Hsu-Robbins and Baum-Katz series that are the basic notion of the classical theory of complete convergence.

Objective. The aim of the paper is to find necessary and sufficient conditions for the almost sure convergence of empirical Baum-Katz series. These conditions are expressed in terms of the existence of certain moments of the underlying random variables.

Methods. For proving our results we develop some new technique based on truncation and studying the truncated random variables. A sufficient ingredient of our approach is to show that the behavior of the truncated versions and the original ones is the same. Despite some similarity between the original series and its empirical version, the methods for achieving the results are quite different.

Results. We find necessary and sufficient conditions for the existence of higher moments of empirical versions. A special attention is paid to the case of multi-indexed sums. The latter case differs essentially from the one-dimensional case, since the space of indices is not completely ordered and thus any approach based on the first hitting moment does not work here.

Conclusions. The results obtained in the paper may serve as a base for further studies of empirical versions that could be used in statistical procedures of estimating an unknown variance.
\end{abstract}

Keywords: complete convergence for sums of independent identically distributed random variables; empirical HsuRobbins and Baum-Katz series; multi-indexed sums; regularly varying weights.

\section{Introduction}

We consider a sequence of partial sums of independent identically distributed random variables and study the complete convergence that generalizes the almost sure convergence and that in probability. The latter two types of convergence of normalized sums are called the law of large numbers and strong law of large numbers, respectively. Studies of the complete convergence are initiated in [1]. Further results on complete convergence can be found in [2-5].

A special attention in our paper is paid to the case of multi-indexed sums and to the rate of convergence. Some results for multi-indexed sums can be found in [6-12]. A survey of earlier results is given in the monograph [13].

Related to our results is the so called empirical convergence that can be used to construct consistent estimators of an unknown variance. The empirical versions of a series represent some random variables whose expectation equals the sum of the corresponding series and this creates an impression that the limiting properties of the series and its empirical version are similar. Sometimes this indeed is the case, however many problems show different behavior of these two objects.
Since the first moment of an empirical version of a series equals its mathematical expectation, a natural question is whether or not the same happens with higher moments. The situation here is challenging, since higher moments may not even exist, while the corresponding series make sense. We find conditions for the existence of higher moments and obtain a relationship between this problem and complete convergence. Moreover, we find conditions for several cases where the weighted empirical versions possess higher moments.

For proving our results we develop some new technique based on truncation and studying the truncated random variables. A sufficient ingredient of our approach is to show that the behavior of the truncated versions and the original ones is the same.

\section{Research objectives}

The main aim of the paper is to study the almost sure convergence of empirical Hsu-Robbins and Baum-Katz series with weights. Conditions for the convergence are expressed in terms of the existence of moments of underlying random variables. The weights are assumed to be regularly varying. Another aim of our investigation is to find neces- 
sary and sufficient conditions for the finiteness of the basic characteristic of empirical series, namely its expectation.

\section{Previous results}

Let $X_{\mathbf{k}}$ be independent identically distributed random variables indexed with $d$-dimensional parameter $\mathbf{k}=\left(k_{1}, \ldots, k_{d}\right)$. Their partial sums are denoted by $S_{\mathrm{n}}$. We consider the empirical analogs of the Hsu-Robbins or Baum-Katz series, namely we consider the random variables

$$
N_{d}(\varepsilon)=\sum_{n=1}^{\infty}|\mathbf{n}|^{\beta} \ell_{1}(|\mathbf{n}|) I\left(\left|S_{n}\right|>|\mathbf{n}|^{\alpha} \varepsilon\right)
$$

depending on parameters $\varepsilon>0, \beta>-1, \quad \alpha>1 / 2$ where $I$ denotes the indicator of a random event, $\ell_{1}$ is a slowly varying function, and $|\mathbf{n}|=\left(n_{1}, \ldots, n_{d}\right)$. We find moment conditions imposed on $X_{\mathbf{k}}$ under which the moments of $N_{d}(\varepsilon)$ exist. Earlier results by Slivka and Severo [14] if $d=1$ and by Gut [7] if $d>1$ are particular cases.

We start with independent identically distributed random variables $X, X_{1}, X_{2}, \ldots$ on some probability space $(\Omega, \Sigma, P)$ with associated partial sums $S_{n}=X_{1}+X_{2}+\ldots+X_{n}, n \in \mathbb{N}$. In this case, there is an equivalence between strong law of large numbers and the existence of certain moments of $X$.

Theorem 1 (Kolmogorov (1933)).

$$
\frac{S_{n}}{n} \stackrel{\text { a.s. }}{\rightarrow} \mu \Leftrightarrow \mathbf{E}|X|<\infty \text { and } \mathbf{E} X=\mu .
$$

(Marcinkiewicz-Zygmund (1937) [15]).

For $1 / 2<\alpha \leq 1$

$$
\frac{S_{n}}{n^{\alpha}} \stackrel{\text { a.s. }}{\rightarrow} \mu \Leftrightarrow \mathbf{E}|X|^{1 / \alpha}<\infty \text { and } \mathbf{E} X=\mu \text {. }
$$

For the case $\alpha=1$ it is well-known that a related equivalence relation holds true in the law of iterated logarithm using the second moment. For the complete convergence (being a somewhat stronger notion of convergence than almost sure convergence), the strong law of large numbers is again equivalent to the existence of an appropriate moment condition.

Theorem 2 (Hsu-Robbins [1] and Erdós [16]).

$$
\sum_{n=1}^{\infty} \mathbf{P}\left(\left|S_{n}-n \mu\right|>\varepsilon n\right)<\infty \Leftrightarrow \mathbf{E} X^{2}<\infty \text { and } \mathbf{E} X=\mu .
$$

for any $\varepsilon>0$
The rate of convergence can be measured by the convergence of the series

$$
\sum_{n=1}^{\infty} n^{\gamma} \mathrm{P}\left(\left|S_{n}-n \mu\right|>\varepsilon n\right) \text { with some } \gamma>0 .
$$

Below is a summary of results of various authors (in particular, Baum and Katz [2], Spitzer [5], see also the book [17]).

Theorem 3. If $1 \geq \alpha>1 / 2$ and $\gamma \alpha>1$ the following two statements are equivalent

i) $\mathbf{E}|X|^{\gamma}<\infty$ and $\mathbf{E} X=0$;

ii) $\sum_{n=1}^{\infty} n^{\gamma \alpha-2} \mathrm{P}\left(\left|S_{n}\right|>\varepsilon n^{\alpha}\right)<\infty$ for any $\varepsilon>0$. In addition, if $\gamma \alpha \geq 1$ then the above two statements are equivalent to

iii) $\sum_{n=1}^{\infty} n^{\gamma \alpha-2} \mathrm{P}\left(\sup _{k \geq n}\left(\frac{\left|S_{k}\right|}{k^{\alpha}}\right)>\varepsilon\right)<\infty$ for any $\varepsilon>0$.

A more general series

$$
\sum_{n=1}^{\infty} n^{\beta} \ell_{1}(n) \mathrm{P}\left(\left|S_{n}\right| \geq n^{\alpha} \varepsilon\right)
$$

is considered by Heyde and Rohatgi [4] with a continuous and strictly increasing slowly varying function $\ell_{1}$ and $\beta \geq-1$.

There are many papers devoted to these series but we do not go deep into the history.

\section{Multidimensional case}

We will now consider the multindex case, i.e., a random field $\left\{X_{\mathbf{k}}, \mathbf{k} \in \mathrm{Z}^{d}\right\}, X$ with independent identically distributed random variables and the index set $Z^{d}, d \geq 2$. We use the positive integer $d$-dimensional lattice with the coordinate-wise partial ordering. As before, we discuss partial sums

$$
S_{\mathbf{n}}=\sum_{\mathbf{k} \leq \mathbf{n}} X_{\mathbf{k}}, \mathbf{n} \in \mathrm{Z}^{d} .
$$

Finally, let $|\mathbf{n}|=n_{1}, \ldots, n_{d}$ be the number of lattice points in the rectangle with the right-upper corner $\mathbf{n}$. To deal with limit theorems one considers summation along the generalized hyperbolas $|\mathbf{k}|=j$ and counts the number of integer points in these sets. Here we have

$$
M(x)=\sum_{|\mathbf{k}| \leq x} 1 \sim \frac{1}{(d-1) !} x(\log x)^{d-1}, x \rightarrow \infty,
$$

whereas $d(j)=M(j)-M(j-1)$ has a less regular behavior and can only be estimated by 


$$
\lim _{j \rightarrow \infty} \frac{d(j)}{j^{\varepsilon}}=0,
$$

whatever $\varepsilon>0$ is (see [18]). However in sums with smooth terms, the function $d(j)$ behaves like the corresponding power of the logarithm, i.e., like $(\log j)^{d-1}$.

The function $M(x)$ is involved in the moment conditions for the strong law of large numbers and complete convergence of multiple sums. The following is an analogue of Theorem 1 for $d>1$.

Theorem 4 (Smythe [11]).

$$
\begin{aligned}
& \frac{S_{\mathbf{n}}}{|\mathbf{n}|} \stackrel{\text { a.s. }}{\rightarrow} \mu \quad \text { as } \quad|\mathbf{n}| \rightarrow \infty \\
\Leftrightarrow & \mathbf{E} M(|X|)<\infty \quad \text { and } \quad \mathbf{E} X=\mu .
\end{aligned}
$$

Note that $\mathbf{E} M(|X|)<\infty \Leftrightarrow \mathbf{E}|X|\left(\log ^{+}|X|\right)^{d-1}<\infty$, where $\log ^{+} x=(1 \vee \log x), \quad x>0$. The Marcinkiewicz-Zygmund normalization $|\mathbf{n}|^{\alpha}, \alpha>\frac{1}{2}$, is considered in [6]. More general normalizations are considered in [10] and [9].

An analogue of Theorem 2 is given next.

Theorem 5 (Smythe [12]).

$$
\begin{gathered}
\sum_{\mathbf{n} \in \mathrm{N}^{d}} \mathbf{P}\left(\left|S_{\mathbf{n}}\right| \geq \varepsilon|\mathbf{n}|\right)<\infty \quad \text { for all } \varepsilon>0 \\
\Leftrightarrow \mathbf{E}|X| M(|X|)<\infty \text { and } \mathbf{E} X=0 .
\end{gathered}
$$

The series with weights $|\mathbf{n}|^{\beta}$ and with the Marcinkiewicz-Zygmund normalization $|\mathbf{n}|^{\alpha}, \quad \alpha>\frac{1}{2}$, are considered in [6]. Some other analogues of Theorem 3 are considered in [10].

\section{Empirical versions of the Heyde-Rohatgi series}

Case of $d=1$. We are interested in the empirical versions of the Baum-Katz and HeydeRohatgi series

$$
\sum_{n=1}^{\infty} n^{\beta} \ell_{1}(n) I\left(\left|S_{n}\right|>n^{\alpha} \varepsilon\right) .
$$

Some questions concerning this series with $\beta=0$ and $\ell_{1}(n)=1, \quad n \geq 1$, are discussed in [14]; some analogs for the case of $d>1$ are considered in [7].

The expectation of series (1) equals the Baum-Katz or Heyde-Rohatgi series depending on whether or not $\ell_{1}$ is involved in (1). Thus the existence of the expectation of the random variable (1) is equivalent to the corresponding moment condition in Theorem 3 or in [4]. In particular, the moment condition depends on $\beta$ and $\ell_{1}$. In contrast, the convergence of series (1) does not depend on either of these parameters. Namely, if $\sum n^{\beta} \ell_{1}(n)$ diverges and $\alpha>\frac{1}{2}$, then (1) is finite almost surely if and only if $\mathbf{E} X=0$ and $\mathbf{E}|X|^{\frac{1}{\alpha}}<\infty$. This result is explained by the Marcinkiewicz-Zygmund strong law of large numbers for sums (see Theorem 1).

For simplicity, consider for a moment the following counting variable

$$
N(\varepsilon):=\sum_{n=1}^{\infty} I\left(\left|S_{n}\right|>n^{\alpha} \varepsilon\right),
$$

the number of times $\left|S_{n}\right|$ is above the threshold $n \varepsilon$ for some (any) $\varepsilon>0$.

Closely related to this random variable is $L(\varepsilon):=\arg \max \left\{n \in \mathbb{N}:\left|S_{n}\right|>n^{\alpha} \varepsilon\right\} \quad$ describing the last time when the threshold is passed. Note that

$$
P(L(\varepsilon) \geq j)=P\left(\sup _{k \geq j} \frac{\left|S_{k}\right|}{k^{\alpha}}>\varepsilon\right) .
$$

Summarizing what has been said above, we prove the following result.

Lemma 1. For and any $\varepsilon>0$,

i) $L(\varepsilon)$ is finite almost surely by Theorem 1.1 if $\mathbf{E}|X|^{\frac{1}{\alpha}}<\infty$ and $\mathbf{E} X=0$.

ii) $\mathbf{E} L(\varepsilon)<\infty$ by Theorem 1.3 with $\gamma=\frac{1}{\alpha}$ provided that $\mathbf{E} X=0$ and $\mathbf{E}|X|^{\frac{2}{\alpha}}<\infty$.

iii) $N(\varepsilon) \leq L(\varepsilon)$ hence $N(\varepsilon)$ is also almost surely finite and its first moment exists provided that $\mathbf{E}|X|^{\frac{2}{\alpha}}<\infty$.

Moments of order $r$ of the random variables $L$ and $N$ can also be investigated.

Theorem 6. Assume that $\alpha=1$ and $r>0$.

Let $r \geq 1$ and $\mathbf{E}|X|^{r+1}<\infty$. Then $\mathbf{E} N(\varepsilon)^{r}<\infty$ for any $\varepsilon>0$ (Slivka and Severo [14]).

Let $0<r \leq 1$. If $\mathbf{E} N(\varepsilon)^{r}<\infty$ for some $\varepsilon>0$, then $\mathbf{E}|X|^{r+1}<\infty$ (Klesov and Stadtmüller [19]). 
Let $r>0$. Then $\mathbf{E}|X|^{r+1}<\infty$ is equivalent to $\mathbf{E} L(\varepsilon)^{r}<\infty$ for all (some) $\varepsilon>0$. Moreover, $\mathbf{E} L(\varepsilon)^{r}<$ $<\infty$ for all $\varepsilon>0$ implies $\mathbf{E} N(\varepsilon)^{r}<\infty$ for all $\varepsilon>0$ (Gut [17]).

Remark 1. Comparing i) and ii) in Theorem 3.1 for the case of $r=1$, we see that the moment condition on $X$ and $N(\varepsilon)$ are equivalent. We conjecture that this is true for all $r>0$.

Case of $d>1$. Now consider for $1 / 2<\alpha \leq 1$ the random variables

$$
N_{d}(\varepsilon):=\sum_{\mathbf{k} \in \mathbb{Z}^{d}} I\left(\left|S_{\mathrm{k}}\right| /|\mathbf{k}|^{\alpha}>\varepsilon\right)
$$

and

$$
L_{d}(\varepsilon)=\arg \max \left\{|\mathbf{k}|:\left|S_{\mathrm{k}}\right| /|\mathbf{k}|^{\alpha}>\varepsilon\right\} .
$$

Note that it no longer holds that $N_{d}(\varepsilon) \leq L_{d}(\varepsilon)$ but we have

$$
N_{d}(\varepsilon) \leq M\left(L_{d}(\varepsilon)\right),
$$

whence $\quad \mathbf{P}\left(L_{d}(\varepsilon)<j\right) \leq \mathbf{P}\left(N_{d}(\varepsilon)<M(j)\right) \quad$ and hence

$$
\begin{gathered}
\mathbf{P}\left(\sup _{|\mathbf{k}| \geq j} \frac{\left|S_{\mathrm{k}}\right|}{|\mathbf{k}|^{\alpha}} \geq \varepsilon\right) \\
=\mathbf{P}\left(L_{d}(\varepsilon) \geq j\right) \geq \mathbf{P}\left(N_{d}(\varepsilon) \geq M(j)\right) \\
\text { for any } j \in N .
\end{gathered}
$$

The following result essentially by Gut [7] is helpfull for the multiindex case and gives a first result about the moments of $N_{d}(\varepsilon)$.

Theorem 7. Let $1 \geq \alpha>1 / 2$.

a) If $\mathbf{E} X=0$ and $\mathbf{E}|X|\left(\log ^{+}|X|\right)^{d-1}<\infty$, then $L_{d}(\varepsilon)<\infty$ and $N_{d}(\varepsilon)<\infty$ almost surely.

b) For $\alpha r>1$, the following statements are equivalent

$$
\begin{array}{r}
\mathbf{E} X=0, \mathbf{E}|X|^{r}\left(\log ^{+}|X|\right)^{d-1}<\infty, \\
\sum_{j=1}^{\infty} j^{\alpha r-2} \mathbf{P}\left(\sup _{\mathrm{k} \geq j}\left|S_{\mathrm{k}}\right| /|\mathbf{k}|^{\alpha}>\varepsilon\right)<\infty
\end{array}
$$

for all $\varepsilon>0$.

c) For $r>0$, we have

$$
\begin{gathered}
\mathbf{E}|X|^{r+1}\left(\log ^{+}|X|\right)^{d-1}<\infty \\
\Leftrightarrow \mathbf{E} L_{d}(\varepsilon)^{\alpha(r+1)-1}<\infty
\end{gathered}
$$

and this implies

$$
\mathbf{E}\left(N_{d}(\varepsilon) /\left(\log N_{d}(\varepsilon)\right)^{d-1}\right)^{\alpha(r+1)-1}<\infty .
$$

The finiteness of $L_{d}(\varepsilon)$ in statement a) follows from the strong law of large numbers for multiindexed random variables by Smythe [11] (see Theorem 2.1). The almost sure finiteness of the random variable $N_{d}(\varepsilon)$ follows from (3).

Part c) is essentially using the probability inequality from above (4) and the Baum-Katz theorem in part a) with $r$ replaced by $r+1$. One may guess that this result is not optimal which we will show below.

\section{Main results: existence of moments of empirical series}

Let $\ell_{1}(\cdot)>0$ denote a slowly varying function on $(0, \infty)$ (see e.g. [20] or [21]). We consider the series

$$
N_{d}(\alpha, \beta ; \varepsilon)=\sum_{\mathbf{k} \in \mathbb{Z}^{d}}|\mathbf{k}|^{\beta} \ell_{1}(|\mathbf{k}|) I\left\{\left|S_{\mathrm{k}}\right| \geq|\mathbf{k}|^{\alpha} \varepsilon\right\}
$$

with some $\beta \geq 0$ and $\alpha>1 / 2$. Without loss of generality we may put $\ell_{1}(x)=1$ on $[0,1)$.

Theorem 8. Let $\ell_{1}$ be a slowly varying function and $\alpha>1 / 2$ and $\beta \geq 0$. Assume that $r \geq 1$. Then $\mathbf{E} X=0$ and

$$
\mathbf{E}|X|^{((\beta+1) r+1) / \alpha}\left(\log ^{+}|X|\right)^{(d-1) r} \ell_{1}\left(|X|^{1 / \alpha}\right)^{r}<\infty
$$

imply

$$
\mathbf{E}\left(N_{d}(\alpha, \beta ; \varepsilon)\right)^{r}<\infty \text { for any } \varepsilon>0 .
$$

The same result holds for negative $\beta$ but we are able to prove it only for integer $r$. The method used in the proof of Theorem 8 does not work for negative $\beta$ and thus we propose another method in the proof of Theorem 9 that works for arbitrary weights in place of $|\mathbf{k}|^{\beta} \ell_{1}(|\mathbf{k}|)$ including the case of $\beta>0$. Nevertheless, we provide a particular proof of Theorem 8, since it is much simpler and allows us to obtain the result for arbitrary $r$ (not only for integer $r$ ).

Theorem 9. Let $\ell_{1}$ be a slowly varying function and $\alpha>1 / 2$ and $-1<\beta<0$. Assume that $r \geq 1$ is an integer number. Then $\mathbf{E} X=0$ and (5) imply (6). 
Remark 2. There is a simple method to prove (6) if $0<r \leq 1$. Namely, given some fields $\left\{w_{n}\right\}$ an $\left\{b_{n}\right\}$ of positive real numbers we have

$$
\mathbf{E}\left(\sum w_{n} I\left(\left|S_{n}\right| \geq b_{n}\right)\right)^{r} \leq \sum w_{n}^{r} \mathbf{P}\left(\left|S_{n}\right| \geq b_{n}\right) .
$$

Applying this result with $w_{n}=|\mathbf{n}|^{\beta} \ell_{1}(|\mathbf{n}|)$, $\beta>-1$ and $b_{n}=\varepsilon|\mathbf{n}|^{\alpha}, \quad \varepsilon>0, \quad 1 / 2<\alpha \leq 1$, we derive from Theorem 11 that (6) holds if $\mathbf{E} X=0$ and

$$
\mathbf{E}|X|^{(r \beta+2) / \alpha}\left(\log ^{+}|X|\right)^{d-1} \ell_{1}\left(|X|^{1 / \alpha}\right)^{r}<\infty .
$$

This moment condition agrees with (5) if $r=1$ but otherwise is worse than (5).

Empirical series without weights. The empirical series without weights, namely

$$
N_{d}(\varepsilon)=\sum_{\mathrm{k}} I\left\{\left|S_{\mathrm{k}}\right| \geq|\mathbf{k}|^{\alpha} \varepsilon\right\},
$$

are of special interest. The finiteness of $N_{d}(\varepsilon)$ for all $\varepsilon>0$ is equivalent to the strong law of large numbers,

$$
\begin{gathered}
N_{d}(\varepsilon)<\infty \text { for all } \varepsilon>0 \\
\Leftrightarrow \mathrm{P}\left(\left|S_{\mathrm{k}}\right| \geq|\mathrm{k}|^{\alpha} \varepsilon \quad \text { i.o. }\right)=0 .
\end{gathered}
$$

The existence of moments of $N_{d}(\varepsilon)$ provides even more information about $S_{k}$.

Theorem 10. Let $\gamma \in R$ and let $\ell_{2}>0$ on $[0, \infty)$ be a slowly varying function. Suppose that $\alpha>1 / 2, \quad r>1$ or $r=1$ and $\left(\ell_{2}(x)\right)^{y}>0$ is nondecreasing, then

$$
\begin{gathered}
\mathbf{E}\left(| X | ^ { ( r + 1 ) / \alpha } ( \operatorname { l o g } ^ { + } | X | ) ^ { ( d - 1 ) r } \left(\ell _ { 2 } \left(|X|^{1 / \alpha}\right.\right.\right. \\
\left.\left.\left.\times(\log |X|)^{d-1}\right)\right)^{\gamma}\right)<\infty \text { and } \mathbf{E}(X)=0
\end{gathered}
$$

implies

$$
\mathbf{E}\left(\left(N_{d}(\varepsilon)\right)^{r}\left(\ell_{2}\left(N_{d}(\varepsilon)\right)\right)^{\gamma}\right)<\infty \text { for any } \varepsilon>0,
$$

where $N_{d}(\varepsilon)$ is defined by (7).

Corollary 1. Let $\ell_{2}(x)=\log (x+2), 1 / 2<\alpha \leq 1$, $r>1$, and $\gamma=-(d-1) r$ in Theorem 10. If

$$
\mathbf{E}|X|^{(r+1) / \alpha}<\infty \text { and } \mathbf{E}(X)=0
$$

then

$$
\mathbf{E}\left(\frac{N_{d}(\varepsilon)}{\left(\log ^{+} N_{d}(\varepsilon)\right)^{d-1}}\right)^{r}<\infty
$$

where $N_{d}(\varepsilon)$ is defined by (7).

Remark 3. Corollary 1 improves a result in [7] where $\alpha=1$ and the assumption

$$
\begin{gathered}
\mathbf{E}|X|^{(r+1)}\left(\log ^{+}|X|\right)^{(d-1)}<\infty \\
\text { and } \mathbf{E}(X)=0
\end{gathered}
$$

is used instead of (8).

The following result provides a sufficient condition for

$$
\mathbf{E}\left(\left(N_{d}(\varepsilon)\right)^{r}<\infty \text { for all } \varepsilon>0 .\right.
$$

Corollary 2. Let $1 / 2<\alpha \leq 1$ and $\ell_{2} \equiv 1$. If

$$
\begin{gathered}
\mathbf{E}|X|^{(r+1) / \alpha}\left(\log ^{+}|X|\right)^{(d-1) r}<\infty \\
\text { and } \mathbf{E}(X)=0,
\end{gathered}
$$

then (9) holds.

\section{Main results: complete convergence}

Let $\ell_{1}(\cdot)>0$ denote a slowly varying function on $(0, \infty)$ as above (see e.g. $[20,21])$ and $X_{1}, X_{2}, \ldots$ be iid copies of $X$ with partial sums $\left(S_{k}\right)$.

Theorem 11. Let $1 / 2<\alpha \leq 1$. Suppose $\beta>-1$ or $\beta=-1$ together with

$$
\ell_{1}(n)(\log n)^{d-1} \geq \delta>0
$$

for some $\delta>0$ and large $n$, then the series

$$
\begin{aligned}
& \sum_{k}|\mathbf{k}|^{\beta} \ell_{1}(|\mathbf{k}|) \mathbf{P}\left(\left|S_{k}\right| \geq|\mathbf{k}|^{\alpha} \varepsilon\right) \\
= & \sum_{k=1}^{\infty} k^{\beta} \ell_{1}(k) d(k) \mathbf{P}\left(\left|S_{k}\right| \geq k^{\alpha} \varepsilon\right)
\end{aligned}
$$

converges for all $\varepsilon>0$ if and only if $\mathbf{E} X=0$ and

$$
\mathbf{E}|X|^{(\beta+2) / \alpha}\left(\log ^{+}|X|\right)^{(d-1)} \ell_{1}\left(|X|^{1 / \alpha}\right)<\infty .
$$

\section{Remark 4.}

1. Note that (12) is still sufficient for (11) if $\alpha>1$ and in case $\beta=-1$ without assuming (10).

2. If $d=1$, this result for increasing continuous functions $\ell_{1}$ is due to Heyde and Rohatgi [4].

3. The example $\ell_{1}(x)=1 / \log ^{+} \log ^{+} x$ obeys the assumption (1) for $d \geq 2$. It is not clear whether condition (10) is necessary for the case $\beta=-1$.

4. By the uniform convergence theorem for slowly varying functions (see Theorem 1.2.1 in [20]) 


$$
\sum_{k=n+1}^{2 n} k^{-1} \ell_{1}(k) d(k) \asymp n^{-1} \ell_{1}(n) \sum_{k=n+1}^{2 n} d(k) .
$$

Since $M(\cdot)$ is a regularly varying function of order 1,

$$
\sum_{k=n+1}^{2 n} d(k)=M(2 n)-M(n) \sim M(n), \quad n \rightarrow \infty .
$$

Thus (10) is equivalent to

$$
\sum_{k=n+1}^{2 n} k^{-1} \ell_{1}(k) d(k) \geq \delta>0
$$

for some $\delta>0$ and large $n$.

\section{Proofs}

Proof of Theorem 8 . We begin with some preparations. For any positive integer $n$ let

$$
\begin{gathered}
I_{n}=\left\{\mathbf{k}:|\mathbf{k}| \leq n \text { and }\left|S_{k}\right| \geq|\mathbf{k}|^{\alpha} \varepsilon\right\}, \\
m=m_{n}=\operatorname{card}\left(I_{n}\right) .
\end{gathered}
$$

This set can be written as

$$
I_{n}=\left\{\mathbf{k}_{1}, \ldots, \mathbf{k}_{m}\right\}
$$

where the elements are ordered along the hyperbolas $|\mathbf{k}|=j, j=1,2, \ldots$, and therein in lexicographic order. In general, i.e., for $d>1$, it is no longer true that always $\left|\mathbf{k}_{v}\right| \geq v$, since several indices $\mathbf{k} \in I_{n}$ at the same "hyperbola" $|\mathbf{k}|=v$ may occur in $I_{n}$. Nevertheless some lower bound for $\left|\mathbf{k}_{v}\right|$ is available. Namely, if $\left|\mathbf{k}_{v}\right|=j$, then

$$
v \leq M(j)=M\left(\left|\mathbf{k}_{v}\right|\right) \leq c\left|\mathbf{k}_{v}\right|\left(\log \left|\mathbf{k}_{v}\right|\right)^{d-1}
$$

with some positive $c>0$ and this implies that

$$
\left|\mathbf{k}_{v}\right| \geq c \frac{v}{\left(\log ^{+} v\right)^{d-1}}
$$

for some different constant $c>0$.

Let $a_{k}=I\left(\left|S_{k}\right| \geq|\mathbf{k}|^{\alpha} \varepsilon\right)$. From the setup just considered we find that, by Hölder's inequality,

$$
\begin{gathered}
\left(\sum_{|\mathbf{k}| \leq n}|\mathbf{k}|^{\beta} \ell_{1}(|\mathbf{k}|) a_{\mathbf{k}}\right)^{r}=\left(\sum_{v=1}^{m}\left|\mathbf{k}_{v}\right|^{\beta} \ell_{1}\left(\left|\mathbf{k}_{v}\right|\right) a_{\mathbf{k}_{v}}\right)^{r} \\
\leq m^{r-1} \sum_{v=1}^{m}\left|\mathbf{k}_{v}\right|^{\beta r} \ell_{1}^{r}\left(\left|\mathbf{k}_{v}\right|\right) a_{\mathbf{k}_{v}} \\
\leq c m^{r-1} \sum_{v=[m / 2]+1}^{m}\left|\mathbf{k}_{v}\right|^{\beta r} \ell_{1}^{r}\left(\left|\mathbf{k}_{v}\right|\right) a_{\mathbf{k}_{v}}=\Sigma_{n} \text { (say) }
\end{gathered}
$$

with some positive constant c. Exploiting (14), there exists some $c>0$ (we use $c$ for different constants without mentioning it furthermore) such that $i \leq c\left|\mathbf{k}_{i}\right|\left(\log \left|\mathbf{k}_{i}\right|\right)^{d-1} \leq c\left|\mathbf{k}_{v}\right|\left(\log \left|\mathbf{k}_{v}\right|\right)^{d-1}$ for $v \geq i$, where $i$ is the integer part of $m / 2$. Thus

$$
\begin{gathered}
\Sigma_{n} \\
\leq c \sum_{v=[m / 2]+1}^{m}\left|\mathbf{k}_{v}\right|^{\beta r+r-1}\left(\log \left|\mathbf{k}_{v}\right|\right)^{(d-1)(r-1)} \ell_{1}^{r}\left(\left|\mathbf{k}_{v}\right|\right) a_{\boldsymbol{k}_{v}} \\
\leq c \sum_{v=1}^{m}\left|\mathbf{k}_{v}\right|^{\beta r+r-1}\left(\log \left|\mathbf{k}_{v}\right|\right)^{(d-1)(r-1)} \ell_{1}^{r}\left(\left|\mathbf{k}_{v}\right|\right) a_{\boldsymbol{k}_{v}} \\
=c \sum_{|\mathbf{k}| \leq|n|}|\mathbf{k}|^{\beta r+r-1}(\log |\mathbf{k}|)^{(d-1)(r-1)} \ell_{1}^{r}(|\mathbf{k}|) a_{\boldsymbol{k}} .
\end{gathered}
$$

Hence we may conclude by monotone convergence and then summation along the hyperbolas $|\mathbf{k}|=k$ that

$$
\begin{gathered}
\boldsymbol{E} N_{d}(\beta, \varepsilon)^{r} \\
\leq c \sum_{\mathbf{k} \in N^{d}}|\mathbf{k}|^{\beta r+r-1} \ell_{1}^{r}(|\mathbf{k}|)(\log |\mathbf{k}|)^{(d-1)(r-1)} \mathbf{P}\left(\left|S_{k}\right|\right. \\
\left.\geq|\mathbf{k}|^{a} \varepsilon\right) \leq c \sum_{k=1}^{\infty} k^{(\beta+1) r-1}(\log k)^{(d-1)(r-1)} \ell_{1}^{r}(|\mathbf{k}|) d(k) \\
\times \mathbf{P}\left(\left|S_{k}\right| \geq k^{a} \varepsilon\right) .
\end{gathered}
$$

Now Theorem 8 follows from Theorem 11.

Proof of Theorem 9. We use the following auxiliary result. Its proof is given after the proof of Theorem 9 is complete.

Lemma 2. Let $\left\{a_{n}\right\}$ be positive numbers such that $a_{n} \in[0, c]$ for some nonrandom $c>0$ and let $\left\{b_{n}\right\}$ be nonnegative numbers. Let $r \geq 1$ be an integer. Put

$$
B_{k}=\sum_{i=1}^{k} b_{i}
$$

Then, for each $n \geq 1$,

$$
\left(\sum_{k=1}^{n} a_{k} b_{k}\right)^{r} \leq c^{r-1} r ! \sum_{k=1}^{n} a_{k} b_{k} B_{k}^{r-1} .
$$

Turning back to the proof of Theorem 9, consider the sequence of random variables $a_{1}, a_{2}, \ldots$ formed as follows: first we place all the indicators $I\left(|S(\mathbf{n})| \geq|\mathbf{n}|^{\alpha} \varepsilon\right)$ with $|\mathbf{n}|=1$ (in fact, there is only one indicator with such a property); the next $d(2)$ random variables among $a_{1}, a_{2}, \ldots$ are the in- 
dicators $I\left(|S(\mathbf{n})| \geq|\mathbf{n}|^{\alpha} \varepsilon\right.$ ) such that $|\mathbf{n}|=2$ (in fact, there are $d(2)$ such indicators) and so on. Then we consider the sequence of numbers $\left\{b_{k}\right\}$ defined as follows: if $M(j-1)<k<M(j)$, then $b_{k}=j^{\beta} \ell_{1}(j)$.

Now, by Lemma 2 ,

$$
\begin{gathered}
\left(\sum_{k=1}^{n} a_{k} b_{k}\right)^{r} \leq r ! \sum_{k=1}^{n} \mathbf{E} a_{k} b_{k} B_{k}^{r-1} \\
\leq r ! \sum_{j=1}^{\infty} \sum_{M(j-1)<k \leq M(j)} \mathbf{E} a_{k} b_{k} B_{k}^{r-1} \\
=r ! \sum_{j=1}^{\infty} \mathbf{P}\left(\left|S_{j}\right| \geq j^{\alpha} \varepsilon\right) j^{\beta} \ell_{1}(j) \sum_{M(j-1)<k \leq M(j)} B_{k}^{r-1} \\
\leq r ! \sum_{j=1}^{\infty} \mathbf{P}\left(\left|S_{j}\right| \geq j^{\alpha} \varepsilon\right) j^{\beta} \ell_{1}(j) B_{M(j)}^{r-1} d(j) .
\end{gathered}
$$

Using Lemma 3 we obtain with a suitable constant $c>0$

$$
\begin{gathered}
B_{M(j)}=\sum_{i=1}^{j} \sum_{M(i-1)<k \leq M(i)} b_{k} \\
=\sum_{i=1}^{j} i^{\beta} \ell_{1}(i) d(i) \leq c j^{\beta+1} \ell_{1}(j)(\log j)^{d-1} .
\end{gathered}
$$

Combining with the latter bound, we find for any $n \in N$

$$
\begin{gathered}
\left(\sum_{k=1}^{n} a_{k} b_{k}\right)^{r} \leq r ! \sum_{j=1}^{\infty} \mathbf{P}\left(\left|S_{j}\right| \geq j^{\alpha} \varepsilon\right) j^{\beta} \ell_{1}(j) \\
\times\left(c j^{\beta+1} \ell_{1}(j)(\log j)^{d-1}\right)^{r-1} d(j) \\
=O(1) \sum_{j=1}^{\infty} \mathbf{P}\left(\left|S_{j}\right|\right. \\
\left.\geq j^{\alpha} \varepsilon\right) j^{(\beta+1)(r-1)+\beta} \ell_{1}^{r}(j)(\log j)^{(d-1)(r-1)} d(j) .
\end{gathered}
$$

Finally, we use Theorem 11 with $\beta \rightarrow(\beta+1)(r-1)+\beta, \ell_{1}(k) \rightarrow \ell_{1}^{r}(k)(\log k)^{(d-1)(r-1)}$.

Thus (5) implies that

$$
\mathbf{E}\left(\sum_{k=1}^{n} a_{k} b_{k}\right)^{r}
$$

is uniformly bounded, whence we derive the statement of Theorem 9, since the terms are nonnegative.

Proof of Le m ma 2. We have

$$
\begin{gathered}
\left(\sum_{k=1}^{n} a_{k} b_{k}\right)^{r}=\sum_{k_{1}=1}^{n} \ldots \sum_{k_{r}=1}^{n} a_{k_{1}} b_{k_{1}} \ldots a_{k_{r}} b_{k_{r}} \\
\leq r ! \sum_{k_{1}=1}^{\infty} a_{k_{1}} b_{k_{1}}\left(\sum_{k_{2}=1}^{k_{1}} \ldots \sum_{k_{r}=1}^{k_{r-1}} a_{k_{2}} b_{k_{2}} \ldots a_{k_{r}} b_{k_{r}}\right) \\
\leq c^{r-1} r ! \sum_{k_{1}=1}^{n} a_{k_{1}} b_{k_{1}}\left(\sum_{k_{2}=1}^{k_{1}} \ldots \sum_{k_{r}=1}^{k_{r-1}} b_{k_{2}} \ldots b_{k_{r}}\right) \\
\leq c^{r-1} r ! \sum_{k_{1}=1}^{n} a_{k_{1}} b_{k_{1}} B_{k_{1}}^{r-1} .
\end{gathered}
$$

Proof of Theorem 10. Without loss of generality we may assume that $x^{r-1}\left(\ell_{2}(x)\right)^{\gamma}$ is nondecreasing and continuous (see Theorem 1.5.3 in [20]). Fix $n$ and use the same notation as in the proof of Theorem 8. In particular, $a_{k}=I\left(\left|S_{k}\right| \geq|\mathbf{k}|^{\alpha} \varepsilon\right)$. Denoting $m=\sum_{|\mathbf{k}| \leq n} a_{k}$ we have

$$
\begin{gathered}
\left(\sum_{|\mathbf{k}| \leq n} a_{\mathbf{k}}\right)^{\gamma}\left(\ell_{2}\left(\sum_{|\mathbf{k}| \leq n} a_{\mathbf{k}}\right)\right)^{\gamma}=m^{\gamma} \ell_{2}(m)^{\gamma} \\
\leq c \sum_{v=1}^{m} v^{r-1} \ell_{2}(v)^{\gamma}
\end{gathered}
$$

(use Karamata's theorem, see e.g. [20])

$$
\begin{aligned}
& \leq c \sum_{v=1}^{m}\left|\mathbf{k}_{v}\right|^{r-1}\left(\log \left|\mathbf{k}_{v}\right|\right)^{(d-1)(r-1)}\left(\ell_{2}\left(|\mathbf{k}|(\log |\mathbf{k}|)^{d-1}\right)\right)^{\gamma} \\
= & c \sum_{|\mathbf{k}| \leq n}|\mathbf{k}|^{r-1}(\log |\mathbf{k}|)^{(d-1)(r-1)}\left(\ell_{2}\left(|\mathbf{k}|(\log |\mathbf{k}|)^{d-1}\right)\right)^{\gamma} a_{\mathbf{k}},
\end{aligned}
$$

where in the second to last line we used (14) and the assumption on $\ell_{2}$. Passing to the expectation and then to the limit as $n \rightarrow \infty$, we obtain

$$
\begin{gathered}
\mathbf{E}\left(\sum_{\mathbf{k} \in \mathbf{N}^{d}} a_{k}\right)^{r}\left(\ell_{2}\left(\sum_{\mathbf{k} \in \mathbf{N}^{d}} a_{k}\right)\right)^{\gamma} \\
\leq c \sum_{\mathbf{k} \in \mathbf{N}^{d}}|\mathbf{k}|^{r-1}(\log |\mathbf{k}|)^{(d-1)(r-1)} \\
\times\left(\ell_{2}\left(|\mathbf{k}|(\log |\mathbf{k}|)^{d-1}\right)\right)^{\gamma} \mathbf{P}\left(\left|S_{k}\right| \geq \mathbf{k}^{\alpha} \varepsilon\right) \\
=c \sum_{k=1}^{\infty} k^{r-1}(\log k)^{(d-1)(r-1)}\left(\ell_{2}\left(k(\log k)^{d-1}\right)\right)^{\gamma} \\
\times d(k) \mathbf{P}\left(\left|S_{k}\right| \geq \mathbf{k}^{\alpha} \varepsilon\right) .
\end{gathered}
$$

Now Theorem 11 completes the proof, note that $\ell_{2}\left(x(\log x)^{d-1}\right)$ is slowly varying again as it 
follows from the definition and the uniform convergence theorem for slowly varying functions (see, e.g., Theorem 1.2.1 in [20]).

Proof of Theorem 11. Assume that (12) holds. First we consider the case of symmetric random variables. Then we deduce the general case from this particular one.

According to the Kahane-Hofmann-Jørgensen inequality (Theorem 7.5 in [17])

$$
\begin{gathered}
\mathbf{P}\left(\left|S_{k}\right| \geq \mathrm{k}^{\alpha} \varepsilon\right) \leq \mathrm{c}_{1} k \mathbf{P}\left(|X| \geq \mathrm{c}_{2} \mathrm{k}^{\alpha}\right) \\
+\mathrm{c}_{3}\left[\mathbf{P}\left(\left|S_{k}\right| \geq \mathrm{c}_{4} \mathrm{k}^{\alpha}\right)\right]^{2^{j}}
\end{gathered}
$$

for any $j \geq 1$, where $c_{1}, c_{2}, c_{3}, c_{4}$ are some positive constants depending on $\varepsilon$ and $j$. Since $\min \{2 \alpha$, $(\beta+1) r+1\}>1$, one can choose a number $\theta$ such that

$$
0<\theta<\min \left\{2, \frac{(\beta+1) r+1}{\alpha}\right\}, \theta \alpha>1 .
$$

Condition (12) implies that the moment $E\left(|X|^{\theta}\right)$ exists, whence by Chebyshev's inequality

$$
\mathbf{P}\left(\left|S_{k}\right| \geq \mathrm{c}_{4} \mathrm{k}^{\alpha}\right) \leq \frac{\mathbf{E}\left|S_{k}\right|^{\theta}}{\left(\mathrm{c}_{4} \mathrm{k}^{\alpha}\right)^{\theta}}=O\left(\frac{1}{k^{\theta \alpha-1}}\right)
$$

in view of the estimate $\mathbf{E}\left|S_{k}\right|^{\theta}=O(1) k \mathbf{E}\left(|X|^{\theta}\right)$. Thus, for sufficiently large $j$,

$$
\sum_{k=1}^{\infty} k^{\beta} \ell_{1}(k) d(k)\left[\mathbf{P}\left(\left|S_{k}\right| \geq \mathrm{c}_{4} \mathrm{k}^{\alpha}\right)\right]^{2^{j}}<\infty
$$

for all $\varepsilon>0$. Furthermore,

$$
\begin{gathered}
\sum_{k=1}^{\infty} k^{\beta+1} \ell_{1}(k)^{r} d(k) \mathbf{P}\left(|X| \geq \mathrm{c}_{2} \mathrm{k}^{\alpha}\right)= \\
=\sum_{j=1}^{\infty} \mathbf{P}\left(c_{2} j^{\alpha} \leq|X|<\mathrm{c}_{2}(j+1)^{\alpha}\right) \sum_{k \leq j} k^{\beta-1} \ell_{1}(k) d(k) .
\end{gathered}
$$

Using the Karamata type Lemma 3 given below, we obtain

$$
\sum_{k \leq j} k^{\beta+1} \ell_{1}(k) d(k) \leq c j^{\beta+2} \ell_{1}(j)(\log j)^{d-1}
$$

for some $c>0$. Now we substitute bound (17) in (16):

$$
\begin{gathered}
\sum_{k=1}^{\infty} k^{\beta+1} \ell_{1}(k) d(k) \mathbf{P}\left(|X| \geq c_{2} k^{\alpha}\right) \\
\leq c \sum_{j=1}^{\infty} \mathbf{P}\left(c_{2} j^{\alpha} \leq|X|\right.
\end{gathered}
$$

$$
\left.<c_{2}(j+1)^{\alpha}\right) j^{\beta+2}(\log j)^{d-1} \ell_{1}(j)<\infty
$$

if (12) holds. This completes the proof for the symmetric case.

Passing to the general case, let $X_{n}^{s}$ denote the symmetrization of the random variable $X_{n}$ and $\left\{S_{n}^{s}\right\}$ be the sequence of partial sums of $\left\{X_{n}^{s}\right\}$. Obviously (12) holds for $X^{s}$, too, and the part of the theorem proved above implies that

$$
\sum_{k=1}^{\infty} k^{\beta} l_{1}(k) d(k) \mathbf{P}\left(\left|S_{k}^{s}\right| \geq k^{\alpha} \varepsilon\right)<\infty
$$

for all $\varepsilon>0$. Finally, we apply the symmetrization inequality,

$$
\mathbf{P}\left(\left|S_{k}^{s}\right| \geq k^{\alpha} \varepsilon\right) \geq \frac{1}{2} \mathbf{P}\left(\left|S_{k}-\operatorname{med}\left(S_{k}\right)\right| \geq k^{\alpha} \varepsilon / 2\right) .
$$

Since (5) implies the existence of the second moment, $\operatorname{med}\left(S_{k}\right)=\mathrm{o}\left(k^{\alpha}\right)$. Combining this with the latter two results, we conclude that

$$
\sum_{k=1}^{\infty} k^{\beta} l_{1}(k) d(k) \sum_{k=1}^{\infty} \mathrm{P}\left(\left|S_{k}^{s}\right| \geq k^{\alpha} \varepsilon\right)<\infty
$$

for all $\varepsilon>0$ which completes the proof of Theorem 11 in the general case.

Now assume that series (11) converges for some $\varepsilon>0$. We start with the symmetric case. Then, by the maximal Lйvy inequality,

$$
\begin{gathered}
\mathbf{P}\left(\max _{k \leq n}\left|X_{k}\right| \geq 2 n^{1 / \alpha} \varepsilon\right) \\
\leq 2 \mathbf{P}\left(\max _{k \leq n}\left|S_{k}\right| \geq n^{1 / \alpha} \varepsilon\right) \leq 4 \mathbf{P}\left(\left|S_{n}\right| \geq n^{1 / \alpha} \varepsilon\right),
\end{gathered}
$$

whence

$$
\sum_{n=1}^{\infty} n^{\beta} l_{1}(n) d(n) \mathbf{P}\left(\max _{k \leq n}\left|X_{k}\right| \geq 2 n^{1 / \alpha} \varepsilon\right)<\infty .
$$

Now, if $\sum_{k=n+1}^{2 n} k^{\beta} l_{1}(k) d(k) \geq \delta>0$ (this holds in particular if $\beta>-1$ ) then it follows by the same arguments as in [3], proof of Theorem 5, $\mathbf{P}\left(\max _{k \leq n}\left|X_{k}\right| \geq 2 n^{1 / \alpha} \varepsilon\right) \rightarrow 0$ that and for some constant $c>0$ and sufficiently large $n \geq 1$,

$$
\begin{gathered}
\mathbf{P}\left(\max _{k \leq n}\left|X_{k}\right| \geq 2 n^{1 / \alpha} \varepsilon\right)=1-\left(1-\mathbf{P}\left(|X| \geq 2 n^{1 / \alpha} \varepsilon\right)\right)^{n} \\
\geq c n \mathbf{P}\left(|X| \geq 2 n^{1 / \alpha} \varepsilon\right)
\end{gathered}
$$

by Lemma A.4.2 in [17] and thus, for some $c>0$, 


$$
\begin{gathered}
\sum_{n=1}^{\infty} n^{\beta} l_{1}(n) d(n) \mathbf{P}\left(\max _{k \leq n}\left|X_{k}\right| \geq 2 n^{1 / \alpha} \varepsilon\right) \\
\geq c \sum_{n=1}^{\infty} n^{\beta+1} l_{1}(n) d(n) \mathbf{P}(|Y| \geq n)
\end{gathered}
$$

where $Y=(X / 2 \varepsilon)^{\alpha}$. Using Lemma 3,

$$
\sum_{n=1}^{\infty} n^{\beta+2} l_{1}(n)(\log n)^{d-1} \mathbf{P}(n \leq|Y|<n)<\infty
$$

which is equivalent to

$$
E|Y|^{\beta+2}\left(\log ^{+}|Y|\right)^{d-1} l_{1}(|Y|)<\infty .
$$

In turn, this is equivalent to (12), since $l_{1}$ is a slowly varying function.

Now we turn to the general case of non necessarily symmetric random variables. Nevertheless series (11) converges for their symmetric versions, $X_{k}^{s}$, say. The part of the theorem already proved implies (12) for the symmetrized version $X^{s}$. This, in turn, implies (12) in the general case, since $l_{1}$ is a slowly varying function.

Lemma 3. Let $v>-1$ and $l$ be a slowly varying function. Then there exists a constant $c>0$ such that

$$
\sum_{k \leq j} k^{v} l(k) d(k) \leq c j^{v+1} l(j)(\log j)^{d-1} .
$$

Proof of Lemma 3. We choose a number $\delta>0$ and a slowly varying function $\tilde{\ell}$ such that $-1<v-\delta<0$ and

1) $l(x) / \tilde{l}(x) \rightarrow 1, x \rightarrow \infty$;

2) $x^{\delta} \tilde{l}(x)$ is nondecreasing.

Such a function $\tilde{l}$ exists in view of [20, Theorem 1.5.4].

Then, for some constants $c^{\prime}>0$ and $c^{\prime \prime}>c^{\prime}$,

$$
\begin{gathered}
\sum_{k \leq j} k^{v} l(k) d(k) \leq c^{\prime} \sum_{k \leq j} k^{v} \tilde{l}(k) d(k) \\
\leq c^{\prime} j \delta \tilde{l}(j) \sum_{k \leq j} k^{v-\delta} d(k) \leq c^{\prime \prime} j^{\delta} l(j) \sum_{k \leq j} k^{v-\delta} d(k) .
\end{gathered}
$$

For the latter sum, we use the partial summation

$$
\begin{aligned}
& \sum_{k \leq j} k^{v-\delta} d(k)=\sum_{k \leq j} k^{v-\delta}(M(k)-M(k-1)) \\
= & j^{v-\delta} M(j)+\sum_{k=1}^{j-1}\left(k^{v-\delta}-(k+1)^{v-\delta}\right) M(k) .
\end{aligned}
$$

Finally, by the mean value theorem and upper bound for $M(k)$,

$$
\begin{gathered}
\sum_{k=1}^{j-1}\left(k^{\nu-\delta}-(k+1)^{\nu-\delta}\right) M(k) \\
\leq O(1) \sum_{k=1}^{j-1} k^{v-\delta-1} M(k) \leq O(1) \sum_{k=1}^{j-1} k^{\nu-\delta}(\log k)^{d-1} \\
\leq O(1) j^{v-\delta+1}(\log j)^{d-1} .
\end{gathered}
$$

Combining with the latter results we complete the proof of Lemma 3.

Lemma 4. Let $v>-1$ and $l$ be a slowly varying function. Then there exists a constant $c>0$ such that

$$
\sum_{k \leq j} k^{v} l(k) d(k) \geq c j^{v+1} l(j)(\log j)^{d-1} .
$$

Proof of Lemma 4 . We choose a number $\delta>0$ and a slowly varying function $\tilde{l}$ such that $v+\delta>0$ and

1) $l(x) / \tilde{l}(x) \rightarrow 1, x \rightarrow \infty$;

2) $x^{-\delta} \tilde{l}(x)$ is nondecreasing.

Such a function $\tilde{l}$ exists in view of [20, Theorem 1.5.4].

Then, for some constants $c^{\prime}>0$ and $c^{\prime \prime}>c^{\prime}$,

$$
\begin{gathered}
\sum_{k \leq j} k^{v} l(k) d(k) \geq c^{\prime} \sum_{k \leq j} k^{v} \tilde{l}(k) d(k) \\
\geq c^{\prime} j^{-\delta} \tilde{l}(j) \sum_{k \leq j} k^{v+\delta} d(k) \geq c^{\prime \prime} j^{-\delta} l(j) \sum_{k \leq j} k^{v+\delta} d(k) .
\end{gathered}
$$

Finally, for some $c^{\prime \prime \prime}>0$,

$$
\begin{gathered}
\sum_{k \leq j} k^{v+\delta} d(k)=\sum_{k \leq j} k^{v+\delta}(M(k)-M(k-1)) \\
=j^{v+\delta} M(j)+\sum_{k=1}^{j-1}\left(k^{v+\delta}-(k+1)^{v+\delta}\right) M(k) \\
\geq j^{v+\delta} M(j) \geq c^{\prime \prime \prime} j^{v+\delta+1}(\log j)^{d-1} .
\end{gathered}
$$

by the upper bound for $M(j)$. Combining with the latter result we complete the proof of Lemma 3 .

\section{Conclusions}

Empirical versions of Hsu-Robbins-Baum-Katz series is an important subject in the theory of complete convergence. The Hsu-Robbins-Baum-Katz series are mathematical expectations of their empirical versions and require stronger conditions for the convergence. The conditions for the almost sure convergence of empirical versions are known only for a limited class of weights. We extend considerably the class of weights and provide sufficient conditions for the almost sure convergence. These sufficient conditions coincide with the necessary conditions in many cases. 
Empirical versions may serve as candidates for estimators of unknown parameters constructed from observations. In the case of constant weights, one obtains an estimator of the variance. The advantage of such estimators is that they are constructed from a binary sequence and are easy to calculate (this is important if the data is big). A disadvantage of such estimators is that they require an infinite sequence of observations (on the othe hand, one can consider an approximate estimator constructed from a finite number of observations). One also has to mention that the consistency of estimators constructed from empirical versions of Hsu-Robbins-Baum-Katz series is known only for the convergence in distribution. Therefore an actual problem in studying statistical properties of Hsu-Robbins-Baum-Katz estimators is to obtain the consistency for other types of convergence.

\section{List of literature}

1. Hsu P.L., Robbins H. Complete convergence and the law of large numbers // Proc. Nat. Acad. Sci. USA. - 1947. - 33. - P. $25-31$.

2. Baum L.E., Katz M. Convergence rates in the law of large numbers // Trans. Amer. Math. Soc. - 1965. - 120. - P. 108-123.

3. Davis J.A. Convergence rates for probabilities of moderate deviations // Ann. Math. Staist. - 1968. - 39. - P. $2016-2028$.

4. Heyde C.C., Rohatgi V.K. A pair of complementary theorems on convergence rates in the law of large numbers // Proc. Camb. Phil. Soc. - 1967. - 63. - P. 73-82.

5. Spitzer F. A combinatorial lemma and its applications to probability theory // Trans. Amer. Math. Soc. - 1956. - 82, № 2. P. 323-339.

6. Gut A. Marcinkiewicz laws and convergence rates in the law of large numbers for random variables with multidimensional indices // Ann. Probab. - 1978. - 6. - P. 469-482.

7. Gut A. Convergence rates for probabilities of moderate deviations for sums of random variables with multidimensional indices // Ann. Probab. - 1980. - 8. - P. 298-313.

8. Gut A. Strong laws for independent identically distributed random variables indexed by a sector // Ann. Prob. - 1983. - 11. P. 569-577.

9. Gut A., Stadtmüller U. An asymmetric Marcinkiewicz-Zygmund LLN for random fields // Stat. Probab. Lett. - 2009. - 79. P. 1016-1020.

10. Klesov O.I. The strong law of large numbers for multiple sums of independent identically distributed random variables // Math. Notes. - 1986. - 38. - P. 1006-1014.

11. Smythe R.T. Strong laws of large numbers for $r$-dimensional arrays of random variables // Ann. Probab. - 1973. - 1. - P. 164-170.

12. Smythe R.T. The sums of independent random variables on the partially ordered sets // Ann. Probab. - 1974. - 2. - P. 906-917.

13. Klesov O.I. Limit Theorems for Multi-Indexed Sums of Random Variables. - New York: Springer, 2014.

14. Slivka J., Severo N.C. On the strong law of large numbers // Proc. Nat. Acad. Sci. U.S.A. - 1970. - 24. - P. $729-734$.

15. Marcinkiewicz J., Zygmund A. Sur les fonctions indépendantes // Fund. Math. - 1937. - 29. - P. 60-90.

16. Erdös P. On a theorem of Hsu and Robbins // Ann. Math. Statist. - 1949. - 20. - P. 286-291; 21. - P. 138.

17. Gut A. Probability: A Graduate Course. Corr. - 2nd ed. - New York: Springer-Verlag, 2013.

18. Hardy G.H., Wright E.M. An Introduction to the Theory of Numbers. - 3rd ed. - Oxford: Oxford University Press, 1954.

19. Klesov O., Stadtmüller U. Existence of moments in the Hsu-Robbins-Erdös theorem // Annales Uni. Sci. Budapest. Sect. Comp. - 2013. - 39. - P. 271-278.

20. Bingham N.H., Goldie Ch., Teugels J. Regular Variation. - Cambridge: Cambridge University Press, 1987.

21. Pseudo-Regular Variation in Generalized Renewal Theory / V.V. Buldygin, K.-H. Indlekofer, O.I. Klesov, J. Steinebach. K.: TBiMC, 2012.

\section{References}

1. P.L. Hsu and H. Robbins, "Complete convergence and the law of large numbers”, Proc. Nat. Acad. Sci. USA, vol. 33, pp. 25-31, 1947.

2. L.E. Baum and M. Katz, "Convergence rates in the law of large numbers", Trans. Amer. Math. Soc., vol. 120, pp. 108-123, 1965.

3. J.A. Davis, "Convergence rates for probabilities of moderate deviations", Ann. Math. Staist., vol. 39, pp. 2016-2028, 1968.

4. C.C. Heyde, and V.K. Rohatgi, "A pair of complementary theorems on convergence rates in the law of large numbers", Proc. Camb. Phil. Soc., vol. 63, pp. 73-82, 1967.

5. F. Spitzer, "A combinatorial lemma and its applications to probability theory", Trans. Amer. Math. Soc., vol. 82, no. 2, pp. 323-339, 1956.

6. A. Gut, "Marcinkiewicz laws and convergence rates in the law of large numbers for random variables with multidimensional indices", Ann. Probab., vol. 6, pp. 469-482, 1978.

7. A. Gut, "Convergence rates for probabilities of moderate deviations for sums of random variables with multidimensional indices”, Ann. Probab., vol. 8, pp. 298-313, 1980. 
8. A. Gut, "Strong laws for independent identically distributed random variables indexed by a sector", Ann. Prob., vol. 11, pp. 569-577, 1983.

9. A. Gut and U. Stadtmüller, "An asymmetric Marcinkiewicz-Zygmund LLN for random fields”, Stat. Probab. Lett., vol. 79, pp. 1016-1020, 2009.

10. O.I. Klesov, "The strong law of large numbers for multiple sums of independent identically distributed random variables", Math. Notes, vol. 38, pp. 1006-1014, 1986.

11. R.T. Smythe, "Strong laws of large numbers for $r$-dimensional arrays of random variables", Ann. Probab., vol. 1, pp. 164-170, 1973.

12. R.T. Smythe, "The sums of independent random variables on the partially ordered sets", Ann. Probab., vol. 2, pp. 906-917, 1974.

13. O.I. Klesov, Limit Theorems for Multi-Indexed Sums of Random Variables. New York: Springer, 2014.

14. J. Slivka and N.C. Severo, "On the strong law of large numbers", Proc. Nat. Acad. Sci. U.S.A., vol. 24, pp. 729-734, 1970.

15. J. Marcinkiewicz and A. Zygmund, "Sur les fonctions indépendantes", Fund. Math., vol. 29, pp. 60-90, 1937.

16. P. Erdős, "On a theorem of Hsu and Robbins", Ann. Math. Statist., vol. 20, pp. 286-291; vol. 21, pp. $138,1949$.

17. A. Gut, Probability: A Graduate Course, 2nd ed. New York: Springer-Verlag, 2013.

18. G.H. Hardy and E.M. Wright, An Introduction to the Theory of Numbers. 3rd ed. Oxford, UK: Oxford University Press, 1954.

19. O. Klesov and U. Stadtmüller, "Existence of moments in the Hsu-Robbins-Erdös theorem", Annales Uni.Sci. Budapest, Sect. Comp., vol. 39, pp. 271-278, 2013.

20. N.H. Bingham et al., Regular Variation. Cambridge, UK: Cambridge University Press, 1987.

21. V.V. Buldygin et al., Pseudo-Regular Variation in Generalized Renewal Theory. Kyiv, Ukraine: TBiMC, 2012.

\section{О.І. Клесов, У. Штадтмюллер}

\section{ІСНУВАННЯ МОМЕНТІВ ЕМПІРИЧНИХ ВЕРСІЙ РЯДІВ СЮЯ-РОББІНСА-БАУМА-КАЦА}

Проблематика. Ми вивчаємо так звану повну збіжність емпіричних аналогів рядів Сюя-Роббінса та Баума-Катца, які $€$ основним об'єктом для досліджень у класичній теорії повної збіжності.

Мета дослідження. Знаходження необхідних та достатніх умов для збіжності майже напевно емпіричних аналогів рядів Баума-Катца. Ці умови виражаються через умови існування певних моментів відповідних випадкових величин.

Методика реалізації. Для доведення основних результатів використовується новий метод, оснований на вивченні зрізаних випадкових величин. Важливою складовою нашого методу $є$ доведення однакової поведінки звичайних рядів та рядів, які відповідають зрізаним випадковим величинам. Незважаючи на зовнішню схожість звичайних рядів Баума-Катца та їх емпіричних аналогів, методи отримання результатів різняться.

Результати дослідження. Знайдено необхідні та достатні умови для існування старших моментів для емпіричних аналогів. Особливу увагу приділено випадку кратних сум. Цей випадок відрізняється від одновимірного тим, що простір індексів не має повного впорядкування, і тому будь-який підхід з використанням моментів першого досягнення в цьому випадку не спрацьовує.

Висновки. Результати, отримані в роботі, можуть стати основою для подальших досліджень емпіричних аналогів, які, своєю чергою, можна використати в статистичних процедурах оцінювання невідомої дисперсії.

Ключові слова: повна збіжність сум незалежних однаково розподілених випадкових величин; емпіричні аналоги рядів Сюя-Роббінса та Баума-Катца; кратні суми; правильно змінні вагові коефіцієнти.

\section{О.И. Клесов, У. Штадтмюллер}

\section{СУЩЕСТВОВАНИЕ МОМЕНТОВ ЭМПИРИЧЕСКИХ ВЕРСИЙ РЯДОВ СЮЯ-РОББИНСА-БАУМА-КАЦА}

Проблематика. Мы изучаем так называемую полную сходимость эмпирических аналогов рядов Сюя-Роббинса и БаумаКатца, которые являются основным объектом для исследований в классической теории полной сходимости.

Цель исследования. Целью исследований является нахождение необходимых и достаточных условий для сходимости почти наверняка эмпирических аналогов рядов Баума-Катца. Эти условия выражаются через условия существования определенных моментов соответствующих случайных величин.

Методика реализации. Для доказательства основных результатов используется новый метод, основанный на изучении срезанных случайных величин. Важной составляющей нашего метода является доведение одинакового поведения обычных рядов и рядов, которые соответствуют срезанным случайным величинам. Несмотря на внешнее сходство обычных рядов Баума-Катца и их эмпирических аналогов, методы получения результатов отличаются.

Результаты исследования. В работе найдены необходимые и достаточные условия для существования старших моментов для эмпирических аналогов. Особое внимание уделено случаю кратных сумм. Этот случай отличается от одномерного тем, что пространство индексов не имеет полного благоустройства, и поэтому любой подход с использованием моментов первого достижения не срабатывает в этом случае.

Выводы. Результаты, полученные в работе, могут стать основой для дальнейших исследований эмпирических аналогов, которые, в свою очередь, можно использовать в статистических процедурах оценивания неизвестной дисперсии.

Ключевые слова: полная сходимость сумм независимых одинаково распределенных случайных величин; эмпирические аналоги рядов Сюя-Роббинса и Баума-Катца; кратные суммы; правильно переменные весовые коэффициенты.

Рекомендована Радою

фізико-математичного факультету

НТУУ "КПІ"
Надійшла до редакції

23 травня 2016 року 
